\title{
Estimation of the faeces output of grazing animals from the concentration of chromium sesquioxide in a sample of faeces
}

\author{
2.* Comparison of estimates from samples taken at fixed times of day with \\ estimates from samples collected from the sward
}

\author{
By J. P. LANGLANDS, $\uparrow$ J. L. CORBETT, $†$ I. McDONALD AND G. W. REID \\ Rowett Research Institute, Bucksburn, Aberdeen
}

\section{(Received 3 August 1962)}

In experiments reported by Langlands, Corbett, McDonald \& Reid (I963) comparisons were made between direct measurements of faeces output and estimates from the concentration of chromium sesquioxide $\left(\mathrm{Cr}_{2} \mathrm{O}_{3}\right)$ in 'grab' samples of faeces taken from the rectum at fixed times of day, regular doses of $\mathrm{Cr}_{2} \mathrm{O}_{3}$ being administered to the animals either in capsules or in a specially prepared paper. In the experiments described now the animals were again dosed with $\mathrm{Cr}_{2} \mathrm{O}_{3}$, but the faeces were not collected for the direct measurement of total output. We studied instead the estimation of faeces output from the concentration of $\mathrm{Cr}_{2} \mathrm{O}_{3}$ in faeces samples collected from the sward and compared it with estimation by grab sampling.

There is some reason to expect that sward sampling will give better estimates of faecal output since, unlike grab sampling, it is essentially a random procedure (Raymond \& Minson, 1955). Identification of the defaecations of a number of animals grazing together can be achieved by dosing each animal with differently coloured particles of polystyrene (Minson, Tayler, Alder, Raymond, Rudman, Line \& Head, 1960). The technique is considerably more laborious than grab sampling and the investigation reported here was carried out to check whether the additional work increased the precision of estimation of faeces output.

A subsidiary purpose was to extend the comparison between two methods of administration of $\mathrm{Cr}_{2} \mathrm{O}_{3}$, in capsules and in paper. In the previous study of grab sampling

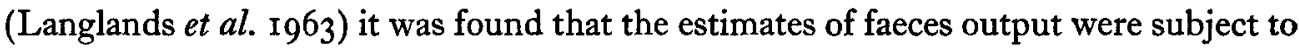
considerable errors, but that these were more stable and less liable to include occasional very large values when $\mathrm{Cr}_{2} \mathrm{O}_{3}$ was given in paper instead of in capsules.

\section{EXPERIMENTAL}

\section{Expt I. Variation in $\mathrm{Cr}_{2} \mathrm{O}_{3}$ concentration between samples from different defaecations}

Doses of $\mathrm{Cr}_{2} \mathrm{O}_{3}$ were given twice daily by balling gun at $09.30 \mathrm{~h}$ and $\mathrm{I} 6.30 \mathrm{~h}$ to each of six 18 -month-old heifers which grazed one pasture for 16 days. At each dosing time three of the heifers received shredded $\mathrm{Cr}_{2} \mathrm{O}_{3}$ paper containing $6.15 \pm 0.06 \mathrm{~g} \mathrm{Cr}_{2} \mathrm{O}_{3}$,

* Paper no. I: Brit. F. Nutr. (1963), r7, 2 1 г.

$\uparrow$ Present address: CSIRO Division of Animal Physiology, Armidale, NSW, Australia. 
and three received gelatin capsules (R. P. Scherer \& Co. Ltd, Slough, Bucks) containing $9.87 \pm 0.04 \mathrm{~g} \mathrm{Cr}_{2} \mathrm{O}_{3}$ in suspension in oil. From the 9 th day all animals were, in addition, dosed twice daily with a gelatin capsule containing approximately $20 \mathrm{~g}$ of polystyrene particles. On day $\mathrm{I} 3$ all faeces on the pasture were marked with sawdust, and on days 14,15 and 16 fresh defaecations were identified and separately sampled and analysed to determine the concentration of $\mathrm{Cr}_{2} \mathrm{O}_{3}$ in organic matter.

\section{Expt 2. Comparison of estimates of faecal output based on sward samples or on grab samples of faeces taken over 5-day periods}

In May and June 1960, twenty milking cows were strip grazed on a single pasture. An electric fence was moved once daily during the afternoon milking, and the area of pasture allotted for the succeeding $24 \mathrm{~h}$ was such that the cows were able to satisfy appetite without difficulty. In August and September 1960 the same pasture was strip grazed in a similar manner by a further twenty cows.

In each season ten of the cows, chosen at random, were dosed twice daily with shredded $\mathrm{Cr}_{2} \mathrm{O}_{3}$ paper and the remaining ten with $\mathrm{Cr}_{2} \mathrm{O}_{3}$ capsules. The paper and the capsules, which provided, respectively, $12.67 \pm 0.16$ and $19.73 \pm 0.08 \mathrm{~g} \mathrm{Cr}_{2} \mathrm{O}_{3}$ daily for each cow, were administered by balling gun after milking at 08.00 and $17.00 \mathrm{~h}$. At these times each day a gelatin capsule containing approximately $20 \mathrm{~g}$ polystyrene particles was also administered to each cow. Only ten different colours of particles were available and each colour was used for two cows. To avoid confusion in the identification of faeces the pairs were separated by grazing two groups of ten cows on adjacent areas of the pasture; $\mathrm{Cr}_{2} \mathrm{O}_{3}$ treatments were distributed at random between the grazing groups.

For each cow outputs of faecal organic matter were estimated from the concentrations of $\mathrm{Cr}_{2} \mathrm{O}_{3}$ in the organic matter of both sward samples and grab samples over four 5 -day periods (nos. I-4) in the spring, with 2-day intervals between periods, and over one 5 -day period (A) in the autumn when a shortage of grass prevented additional observations.

During the evening milking at the beginning of every period all faeces on the pasture were marked with sawdust. Each day for the following 5 days identifiable fresh defaecations were collected separately for each cow. To allow for differences in size between single defaecations, as much faeces was taken as could be collected uncontaminated with herbage or soil; the work occupied about 3 man-hours daily. The faeces collected each day, generally from about ten to twelve defaecations for each cow, were thoroughly mixed, and samples of I $\mathrm{kg}$ were taken and combined to give a total of $5 \mathrm{~kg}$ for each cow over the 5 days. After further thorough mixing, subsamples were analysed.

Grab samples of $300 \mathrm{~g}$ were taken at ten consecutive milking times in every period beginning on the evening when faeces on the pasture were marked with sawdust. Combined samples for each cow, a total of $3 \mathrm{~kg}$ over the 5 days, were thoroughly mixed and then analysed. 


\section{Determination of $\mathrm{Cr}_{2} \mathrm{O}_{3}$ in faeces}

The concentration of $\mathrm{Cr}_{2} \mathrm{O}_{3}$ in the organic matter of the faeces samples was determined by a modification (Commonwealth Bureau of Pastures and Field Crops, 1961) of the method of Christian \& Coup (1954).

\section{RESULTS}

Expt 1. Variation in $\mathrm{Cr}_{2} \mathrm{O}_{3}$ concentration between samples from different defaecations

Measurements of $\mathrm{Cr}_{2} \mathrm{O}_{3}$ concentration $\left(C_{S}\right)$ were made on from six to thirteen samples from individual defaecations attributable to each of the six heifers on each of 3 days. Each value was combined with that for the daily dose of $\mathrm{Cr}_{2} \mathrm{O}_{3}(D)$ to give an estimate $\left(D / C_{S}\right)$ of the day's output of faeces. The variability in these estimates is shown in Table $\mathrm{I}$ in the form of coefficients of variation. For three of the six heifers the variability changed significantly from day to day $(P<0.05)$, presumably because

Table 1. Expt 1. Errors in sward sampling. Coefficients of variation (\%) of estimates of faeces output $\left(D / C_{S}\right)$ calculated from the daily dose of $\mathrm{Cr}_{2} \mathrm{O}_{3}(D)$ and the mean concentration of $\mathrm{Cr}_{2} \mathrm{O}_{3}$ in samples of faeces taken from individual defaecations $\left(C_{S}\right)$ collected on each of 3 days for each of six grazing heifers

\begin{tabular}{|c|c|c|c|c|c|c|}
\hline \multirow[b]{2}{*}{ Day } & \multicolumn{3}{|c|}{ Heifers given $\mathrm{Cr}_{2} \mathrm{O}_{3}$ in paper } & \multicolumn{3}{|c|}{ Heifers given $\mathrm{Cr}_{2} \mathrm{O}_{3}$ in capsules } \\
\hline & No. I & No. 2 & No. 3 & No. 4 & No. 5 & No. 6 \\
\hline I & $8 \cdot 5(\mathrm{IO})$ & $5 \cdot 6(9)$ & $I I \cdot I(8)$ & $12 \cdot 6(9)$ & $17 \cdot 6(8)$ & $14 \cdot 2(12)$ \\
\hline 2 & $17.9(13)$ & $12 \cdot 0(9)$ & $5.9(8)$ & $14.6(9)$ & $14 \cdot 6(9)$ & $6.4(12)$ \\
\hline 3 & 14.0 (10) & $7 \cdot 1$ (ro) & $7 \cdot 0(8)$ & $20 \cdot 4(9)$ & $14 \cdot 5(6)$ & $9 \cdot 5(\mathrm{II})$ \\
\hline$(1+2+3)$ & $14 \cdot 4(33)$ & $8 \cdot 4(28)$ & $7 \cdot 9(24)$ & $16.4(27)$ & $15.8(23)$ & $117(35)$ \\
\hline Mean & & II $\cdot 0$ & & & 14.4 & \\
\hline
\end{tabular}

Figures in parentheses are the numbers of defaecations sampled.

of irregularities in grazing behaviour. There was no indication of any relationship between the variability and the number of defaecations from which it was derived. The variability over the whole 3 days tended to be less for heifers given paper than for those given capsules. With the small numbers of animals involved the difference was not significant, but it is in line with the general finding that there is greater regularity in $\mathrm{Cr}_{2} \mathrm{O}_{3}$ excretion after dosing with paper than with capsules; separate mean variabilities are therefore given for the two groups of animals.

The results of Expt I can be used for approximate calculations of the errors involved in sward sampling. The component of error associated with the sampling process, as a percentage standard error, may be described approximately by the expressions

$$
\left.\mathrm{I} \mathrm{I} \cdot \mathrm{O} /\left[\frac{\mathrm{I}}{n}\left(\mathrm{I}-\frac{n}{T}\right)\right] \text { and } \mathrm{I} 4 \cdot 4 \sqrt{\frac{\mathrm{I}}{n}}\left(\mathrm{I}-\frac{n}{T}\right)\right]
$$

for dosing with $\mathrm{Cr}_{2} \mathrm{O}_{3}$ in paper and in capsules respectively, where the values $\mathrm{I} \cdot \mathrm{O}$ and 14.4 are mean coefficients of variation, taken from Table $\mathrm{I}, \boldsymbol{n}$ is the number of defae- 
cations from which samples are obtained and $T$ is the total number of defaecations within the period concerned. The ratio $n / T$ may be described as the sampling fraction. These expressions show the effect of variability in $\mathrm{Cr}_{2} \mathrm{O}_{3}$ concentration between defaecations and of failure to sample from all defaecations, but take no account of the possibility that sampling from individual defaecations may be unrepresentative, or of the effects of variation in weight between defaecations. Table 2 shows the estimated

Table 2. Expt $\mathrm{I}$. Short-term component of random error in the estimation of the faeces output of a cow from the $\mathrm{Cr}_{2} \mathrm{O}_{3}$ concentration in sward samples of faeces, expressed as percentage standard error from the results, forty defaecations/3 days being assumed

\begin{tabular}{|c|c|c|c|c|}
\hline \multirow{2}{*}{$\begin{array}{c}\text { Sampling } \\
\text { fraction of } \\
\text { defaecations } \\
\left(\frac{\text { no. samples }}{\text { total no. }}\right)\end{array}$} & \multicolumn{2}{|c|}{ 3-day sampling period } & \multicolumn{2}{|c|}{ I5-day sampling period } \\
\hline & $\begin{array}{c}\mathrm{Cr}_{2} \mathrm{O}_{3} \text { in } \\
\text { paper }\end{array}$ & $\begin{array}{l}\mathrm{Cr}_{2} \mathrm{O}_{3} \text { in } \\
\text { capsules }\end{array}$ & $\begin{array}{c}\mathrm{Cr}_{2} \mathrm{O}_{3} \text { in } \\
\text { paper }\end{array}$ & $\begin{array}{l}\mathrm{Cr}_{2} \mathrm{O}_{3} \text { in } \\
\text { capsules }\end{array}$ \\
\hline 0.9 & \pm 0.6 & \pm 0.8 & \pm 0.3 & \pm 0.3 \\
\hline 0.7 & $\pm I \cdot I$ & $\pm I \cdot 5$ & \pm 0.5 & \pm 0.7 \\
\hline 0.5 & $\pm 1 \cdot 7$ & $\pm 2 \cdot 3$ & \pm 0.8 & \pm 10 \\
\hline 0.3 & $\pm 2 \cdot 7$ & \pm 3.5 & $\pm x \cdot 2$ & $\pm \mathrm{I} \cdot 6$ \\
\hline 0.1 & $\pm 5 \cdot 2$ & \pm 6.8 & $\pm 2 \cdot 3$ & $\pm 3 \cdot 0$ \\
\hline
\end{tabular}

Table 3. Expt 1. Short-term, long-term and total random errors in the estimation of the faeces output of a cow from $\mathrm{Cr}_{2} \mathrm{O}_{3}$ concentration in sward samples of faeces, expressed as percentage standard errors from the results and from an estimate of $\pm 8 \%$ for the longterm component over 3-day periods, and on the assumption that the sward sample represents a fraction 0.7 of the total number of defaecations, that total being assumed to be forty $/ 3$ days

\section{Length of sampling period (days)}

5
7
10
14
20

$\overbrace{\begin{array}{c}\mathrm{Cr}_{2} \mathrm{O}_{3} \text { in } \\ \text { paper }\end{array}}^{\text {Short-term }} \underbrace{\text { component }}_{\begin{array}{c}\mathrm{Cr}_{2} \mathrm{O}_{3} \text { in } \\ \text { capsules }\end{array}}$

\pm 0.9
\pm 0.7
\pm 0.6
\pm 0.5
\pm 0.4

Long-term
component
$\pm 6 \cdot 2$
$\pm 5 \cdot 2$
$\pm 4 \cdot 4$
$\pm 3 \cdot 7$
$\pm 3 \cdot 1$

Total random error

\begin{tabular}{|c|c|}
\hline $\begin{array}{c}\mathrm{Cr}_{2} \mathrm{O}_{3} \text { in } \\
\text { paper }\end{array}$ & $\begin{array}{l}\mathrm{Cr}_{2} \mathrm{O}_{3} \text { in } \\
\text { capsules }\end{array}$ \\
\hline $\pm 6 \cdot 3$ & $\pm 6 \cdot 3$ \\
\hline \pm 5.3 & \pm 5.3 \\
\hline \pm 4.4 & \pm 4.5 \\
\hline \pm 3.7 & \pm 3.8 \\
\hline $\pm 3 \cdot I$ & $\pm 3 \cdot 2$ \\
\hline
\end{tabular}

short-term standard errors, as percentages, for various sampling fractions over periods of 3 and 15 days, forty defaecations per animal per 3 days being assumed. An additional component of error may result when $\mathrm{Cr}_{2} \mathrm{O}_{3}$ excretion does not equal $\mathrm{Cr}_{2} \mathrm{O}_{3}$ intake over the period of estimation. The values in Table I of Langlands et al. (1963) show that this error, expressed as a coefficient of variation, might be expected to approximate to $\pm 8 \%$ for a 3 -day period, and the detailed results indicated that values for periods of $n$ days could be taken to be $\pm 8 \sqrt{ }(3 / n) \%$. Estimates of the combined short- and long-term errors are given in Table 3 for collection periods of from 5 to 20 days, a sampling fraction of 0.7 which could be achieved fairly readily in practice being assumed. Clearly the long-term error will be predominant when faeces output has to be estimated, but for reasons to be discussed later only part of the error may be relevant to subsequent estimates of feed intake. 
Expt 2. Comparison of estimates of faecal output based on sward samples and on grab samples of faeces, taken over 5-day periods

Estimates of the daily output of faecal organic matter were obtained from the $\mathrm{Cr}_{2} \mathrm{O}_{3}$ concentrations in both the sward samples and the grab samples of faeces for each cow in each 5 -day period. Table 4 shows mean values and standard deviations of these estimates for both groups of ten cows, those dosed with paper and those dosed with capsules. Mean differences between the corresponding estimates based on sward samples and grab samples are given in Table 5, with their standard errors calculated on a between-cow basis.

Table 4. Expt 2. Mean values and between-cow standard deviations ( 9 df) of estimates of faecal organic matter output ( $\mathrm{kg} /$ day) for groups of ten cows, calculated for each cow from the $\mathrm{Cr}_{2} \mathrm{O}_{3}$ concentration in sward samples and in grab samples of faeces over periods of 5 days

\begin{tabular}{|c|c|c|c|c|}
\hline \multirow[b]{2}{*}{$\begin{array}{c}\text { Period } \\
\text { no. }\end{array}$} & \multicolumn{2}{|c|}{ Cows given $\mathrm{Cr}_{2} \mathrm{O}_{3}$ in paper } & \multicolumn{2}{|c|}{ Cows given $\mathrm{Cr}_{2} \mathrm{O}_{3}$ in capsules } \\
\hline & $\begin{array}{c}\text { Sward } \\
\text { samples }\end{array}$ & $\begin{array}{c}\text { Grab } \\
\text { samples }\end{array}$ & $\begin{array}{c}\text { Sward } \\
\text { samples }\end{array}$ & $\begin{array}{c}\text { Grab } \\
\text { samples }\end{array}$ \\
\hline I & $I \cdot 98 \pm 0.30$ & $2.01 \pm 0.35$ & $1.94 \pm 0.27$ & $1.93 \pm 0.27$ \\
\hline 2 & $2 \cdot 37 \pm 0.28$ & $2 \cdot 35 \pm 0.35$ & $2 \cdot 20 \pm 0 \cdot 30$ & $2 \cdot 26 \pm 0.34$ \\
\hline 3 & $2.64 \pm 0.45$ & $2 \cdot 62 \pm 0.45$ & $2 \cdot 35 \pm 0.40$ & $2.45 \pm 0.58$ \\
\hline 4 & $3.08 \pm 0.47$ & $2 \cdot 94 \pm 0.53$ & $2 \cdot 88 \pm 0.54$ & $2 \cdot 78 \pm 0 \cdot 46$ \\
\hline$A^{*}$ & $2 \cdot 35 \pm 0.24$ & $2 \cdot 40 \pm 0.3 I$ & $2.54 \pm 0.24$ & $2.57 \pm 0.24$ \\
\hline
\end{tabular}

Table 5. Expt 2. Mean values with their standard errors (9 df) for differences between estimates of output of faecal organic matter (kg/day), by sward sampling and grab sampling, given in Table 4

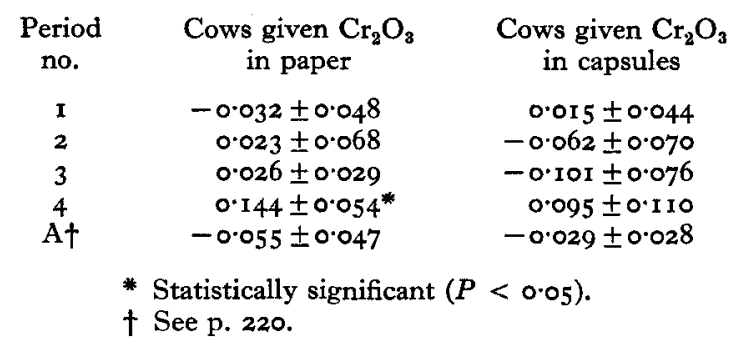

The standard deviations of the estimates based on sward samples (Table 4) are, with one exception, less than or equal to the standard deviations of the corresponding estimates based on grab samples, indicating that the random error associated with sward sampling was less than that associated with grab sampling. The magnitude of the effect must be estimated indirectly since the nature of the experiment precluded direct measurement of faecal output by total collection. It may be assumed that the standard deviations in Table 4 are estimates of $\sqrt{ }\left(S_{C}^{2}+S_{S}^{2}\right)$ or of $\sqrt{ }\left(S_{C}^{2}+S_{G}^{2}\right)$, where $S_{C}^{2}$ is the variance component arising from differences between cows in true faecal output, and $S_{S}^{2}$ and $S_{G}^{2}$ are the additional variance components arising from random error of 
estimation from sward samples and grab samples of faeces respectively. The mean difference between the squared $\mathrm{SD}$ with grab samples and the corresponding squared SD with sward samples was $0.030\left(\mathrm{~kg} /\right.$ day) ${ }^{2}$ (Table 4 ) and may be taken as an estimate of $S_{G}^{2}-S_{S}^{2}$. From the results of Expt I it was estimated that over a 5-day period $S_{S}$ would be $\pm 6.3 \%$ of the mean faecal output (Table 3 ). With a daily output of about $2.4 \mathrm{~kg}$ (Table 4 ), $S_{S}$ would be estimated as $\pm 0.15 \mathrm{~kg} /$ day, and hence, from the equation $S_{\theta}^{2}-S_{S}^{2}=0.030, S_{G}$ would be estimated as $\pm 0.23 \mathrm{~kg} /$ day. Some idea of the value of sward sampling as against grab sampling may be obtained by taking the inverse ratio of their error variances, in this instance $\left[0.23 / 0 \cdot 1_{5}\right]^{2}$, i.e. $2 \cdot 4$, suggesting that, over 5-day periods, more than twice as much information is obtainable from sward sampling as from grab sampling.

\section{DISCUSSION}

The results of these experiments indicate that the random error in estimating faeces outputs may be appreciably less by sward sampling than by grab sampling. Because of the more random nature of the process, sward sampling must also introduce into the estimation of faeces outputs less bias than does grab sampling, but little evidence of this advantage was found in Expt 2, only one difference out of ten being significant (Table 5). However, the bias in estimates from grab sampling has been shown to vary considerably from trial to trial (Langlands et al. I963) and may have been small in Expt 2. No direct check can be made for bias in estimates from sward sampling, since the technique, unlike that of grab sampling, is obviously incompatible with the total collection of faeces. An indirect check could be made on a between-animal basis by introducing an additional treatment group from which a total collection of faeces could be made; large numbers of animals would be required because of the considerable variation in faeces output from animal to animal. A cross-over experiment to obtain a within-animal comparison would probably require fewer animals but would be suitable only under conditions in which faeces output did not change greatly from period to period.

When as many defaecations as possible are sampled, as in Expt 2, the labour involved in sward sampling is considerably greater than in grab sampling, but the values in Table 2 suggest that the sampling fraction, and so the labour, could be reduced without greatly increasing the total error of estimation of faeces output. It would be necessary to use a random procedure for deciding which defaecations should be sampled. Restriction of sampling to predetermined areas of the pasture, as in Raymond \& Minson's (1955) 'ring-sampling' technique, might prove a satisfactory solution.

When sward sampling is impracticable, and grab sampling is employed, the results presented here and in the previous paper (Langlands et al. 1963) suggest that the doses of $\mathrm{Cr}_{2} \mathrm{O}_{3}$ should be given in paper rather than in capsules. Although in some trials the choice may make little difference, in others it is likely that the use of capsules will result in much greater variability in the concentration of $\mathrm{Cr}_{2} \mathrm{O}_{3}$ in the faeces, apparently because the efficiency with which $\mathrm{Cr}_{2} \mathrm{O}_{3}$ is mixed with digesta in the reticulo- 
rumen is altered much more readily by changes in the pattern of feeding when capsules rather than paper are used. Thus in a trial (Corbett, Greenhalgh, McDonald $\&$ Florence, 1960) with sheep hand-fed thrice daily and dosed with $\mathrm{Cr}_{2} \mathrm{O}_{3}$ once daily at a time not coinciding with feeding, the mean variability in faecal $\mathrm{Cr}_{2} \mathrm{O}_{3}$ concentration expressed as a coefficient of variation was \pm I I \% with the paper but $\pm 33 \%$ with capsules. In further trials with sheep hand-fed twice daily and dosed immediately before one or both feeds (Langlands, 1962), variability with paper was again $\pm 11 \%$ in one trial and $\pm 9 \%$ in another, whereas with capsules the mean variabilities were \pm 15 and $\pm 16 \%$ respectively. The highest value for a sheep dosed with paper was $\pm 15 \%$ and for one dosed with capsules $\pm 26 \%$. In addition, in the trials reported by Langlands et al. (1963) it was found that when grazing was unrestricted paper gave the smaller variabilities, but when a large amount of hay was given each day immediately after dosing the two types of dose gave similar results. When hay was given the conditions were similar to those in Expt 2 described here, in which the cows were returned to the pasture immediately after dosing and at once began to graze intensively; again there was little difference in the variabilities recorded with capsules and paper.

Although the method of administration of $\mathrm{Cr}_{2} \mathrm{O}_{3}$ will often be of great importance for obtaining reliable estimates of faeces output from grab samples, it may be of little importance when samples are collected from the sward, since the greater part of the error in estimates based on sward samples arises from long-term fluctuations rather than from changes in marker concentration from hour to hour (Table 3 ). Whether to dose with $\mathrm{Cr}_{2} \mathrm{O}_{3}$ in paper or in capsules, when sward sampling is practised, may therefore be decided largely by the relative convenience of the two methods of dosing. There is, however, a possible argument against this conclusion. The estimation of faeces output is not an end in itself, but is usually a first step in a series of calculations. If it is used together with an estimate of digestibility to estimate the food intake of the animal in a corresponding period, the resultant estimate of intake might conceivably be better than one derived from a total collection of faeces and the same estimate of digestibility. In this context the long-term component of error shown in Table 3 might be ascribed in part to the faeces output and not wholly to the estimate from $\mathrm{Cr}_{2} \mathrm{O}_{3}$ concentration, in the sense that the error reflects a lack of correspondence between intake and output arising from fluctuations in rate of passage of digesta. The estimate from $\mathrm{Cr}_{2} \mathrm{O}_{3}$ concentration might then, as suggested by Raymond \& Minson (1955), be regarded as an estimate not of the faeces output in a standard period, but of the faeces output derived from the feed intake in a standard period. In so far as this argument can be accepted, it strengthens the general conclusions that sward sampling is less susceptible to error than grab sampling and that it is preferable to administer doses of $\mathrm{Cr}_{2} \mathrm{O}_{3}$ in paper rather than in capsules. 
SUMMARY

I. Two experiments were made in which grazing cattle were dosed twice daily with standard quantities of finely divided chromium sesquioxide $\left(\mathrm{Cr}_{2} \mathrm{O}_{3}\right)$ either in gelatin capsules or incorporated in a specially prepared paper.

2. In Expt I measurements of $\mathrm{Cr}_{2} \mathrm{O}_{3}$ concentration $\left(C_{S}\right)$ were made on samples from six to thirteen individual defaecations attributable to each of six heifers on each of 3 days; these sward samples were collected from the pasture. In Expt 2 estimates of faecal output from $\mathrm{Cr}_{2} \mathrm{O}_{3}$ concentrations in combined sward samples were obtained for each of twenty dairy cows in five 5 -day periods and were compared with corresponding estimates obtained from $\mathrm{Cr}_{2} \mathrm{O}_{3}$ concentrations in combined samples of faeces from the rectum (grab samples) taken at fixed times twice daily.

3. The results indicated that the random error was appreciably less in the estimates of faecal output from the sward samples. The errors were calculated of estimates obtained from sward samples collected over periods of various lengths and representing varying numbers of defaecations. It was concluded that paper is to be preferred to capsules when grab sampling is practised but that the advantage of the paper when sward sampling is practised may be relatively slight.

We thank Miss S. Gavin and Mr E. Florence for the chemical analyses. One of us (J. P. L.) was in receipt of a postgraduate scholarship from the Ministry of Agriculture, Fisheries and Food.

\section{REFERENCES}

Christian, K. R. \& Coup, M. R. (1954). N.Z. F. Sci. Tech. A, 36, 328.

Commonwealth Bureau of Pastures and Field Crops (r96r). Bull. Bur. Past., Hurley, no. 45.

Corbett, J. L., Greenhalgh, J. F. D., McDonald, I. \& Florence, E. (1960). Brit. F. Nutr. 14, 289.

Langlands, J. P. (1962). Energy intake and its utilisation for maintenance by the intensively grazed ruminant. Ph.D. Thesis, University of Aberdeen.

Langlands, J. P., Corbett, J. L., McDonald, I. \& Reid, G. W. (1963). Brit. F. Nutr. 17, 2 I.

Minson, D. J., Tayler, J. C., Alder, F. E., Raymond, W. E., Rudman, J. E., Line, C. \& Head, M. J. (1960). F. Brit. Grassl. Soc. 15, 86.

Raymond, W. F. \& Minson, D. J. (1955). F. Brit. Grassl. Soc. 10, 282. 